\title{
Mechanical Compaction of Porous Sandstone
}

\author{
T. F. Wong ${ }^{1}$ and P. Baud' \\ 1 Department of Geosciences, State University of New York, Stony Brook, NY $11794-2100$ - United States \\ e-mail: wong@horizon.ess.sunysb.edu - pbaud@horizon.ess.sunysb.edu
}

\begin{abstract}
Résumé - Compaction mécanique des grès poreux - Pour de nombreux problèmes de tectonique et d'ingénierie de réservoir, la capacité à prévoir à la fois la fréquence, l'ampleur de la déformation inélastique et les ruptures repose sur une compréhension fondamentale de la phénoménologie et de la micromécanique de compaction dans les roches-réservoirs. Cet article présente les résultats de recherches récentes sur la compaction mécanique des grès poreux. On insiste plus particulièrement sur la synthèse des données de laboratoire, la caractérisation microstructurale quantitative de l'endommagement, ainsi que sur les modèles théoriques basés sur un contact élastique et sur la mécanique de la rupture. Les attributs mécaniques de la compaction sur des échantillons initialement secs et saturés ont été étudiés sous des chargements hydrostatiques et non hydrostatiques dans une large gamme de pression. Les sujets spécifiques étudiés ici incluent : la comparaison des données d'émission acoustique et mécanique avec une théorie de la plasticité; le contrôle microstructural du début et du développement de la compaction; l'écrouissage et l'évolution spatiale de l'endommagement lors de la compaction; enfin, l'effet affaiblissant de l'eau sur le seuil de compaction et l'évolution de la porosité.
\end{abstract}

Mots-clés : essais triaxiaux, porosité, émissions acoustiques, endommagement microstructural, compaction, dilatance.

\begin{abstract}
Mechanical Compaction of Porous Sandstone - In many reservoir engineering and tectonic problems, the ability to predict both the occurrence and extent of inelastic deformation and failure hinges upon a fundamental understanding of the phenomenology and micromechanics of compaction in reservoir rock. This paper reviews recent research advances on mechanical compaction of porous sandstone, with focus on the synthesis of laboratory data, quantitative microstructural characterization of damage, and theoretical models based on elastic contact and fracture mechanics. The mechanical attributes of compaction in nominally dry and saturated samples have been studied under hydrostatic and nonhydrostatic loadings over a broad range of pressure conditions. Specific topics reviewed herein include: comparison of mechanical and acoustic emission data with continuum plasticity theory; microstructural control of onset and development of compaction; strain hardening and spatial evolution of damage during compaction; and the weakening effect of water on compactive yield and porosity change.

Keywords: triaxial experiments, porosity, acoustic emissions, microstructure damage, compaction, dilatancy.
\end{abstract}

\section{INTRODUCTION}

A fundamental understanding of mechanical compaction is central to a number of issues in reservoir and geotechnical engineering, for which deformation and fluid transport are intimately related. For example, hydrocarbon extraction reduces pore pressure and may thus cause an increase in the effective stress (e.g., Teufel et al., 1991). For very porous or weakly consolidated reservoirs, the increase in effective stress may be sufficient to cause inelastic deformation of the reservoir rock (e.g., Jones and Leddra, 1989; Goldsmith, 1989). The consequences of such inelastic compaction can be economically severe and include surface subsidence and various production problems (e.g., Smits et al., 1988; Fredrich et al., 1998). Significant reduction of permeability may also accompany the compaction (Zhu and Wong, 1997b). 
In less spectacular cases, shear deformation in response to pore pressure drawdown may be restricted to the near wellbore region. In such cases, the inelastic deformation may lead to casing failure or solids production, both of which may be serious enough to force well abandonment (e.g., Fredrich et al., 1998). Knowledge of the compactive response of rock masses to stress is also relevant to various geotechnical applications, including drilling technology (e.g., Thiercelin, 1989; Suarez-Rivera et al., 1990), and nuclear waste isolation (e.g., Davis, 1991).

The ability to predict both the occurrence and extent of inelastic deformation in these applications is an essential facet of reservoir and geotechnical engineering that hinges upon a fundamental understanding of the phenomenological description and micromechanical processes associated with compaction in porous rocks. This paper reviews recent advances in rock mechanics research on the mechanical compaction of porous sandstone, with focus on the synthesis of laboratory data, quantitative characterization of damage, and theoretical models. Specific topics include: comparison of mechanical and acoustic emission data with continuum plasticity theory; microstructural control of onset and development of compaction; spatial evolution of damage during strain hardening and compaction; and the weakening effect of water on compactive yield and porosity change.

We will adopt the convention that compressive stresses and compactive strains (i.e., shortening and porosity decrease) are positive, and we will denote the maximum and minimum (compressive) principal stresses by $\sigma_{1}$ and $\sigma_{3}$, respectively. The pore pressure will be denoted by $P_{p}$, and the difference between the confining pressure $\left(P_{c}=\sigma_{2}=\sigma_{3}\right)$ and pore pressure will be referred to as the "effective pressure" $\mathrm{P}_{e f f}$. Experimental data were all acquired under fully "drained" conditions. In all micrographs of deformed samples, the principal stress $\sigma_{1}$ is vertical.

\section{ONSET AND DEVELOPMENT OF SHEAR-ENHANCED COMPACTION: INFLUENCE OF PRESSURE AND MICROSTRUCTURE}

The pressure and temperature conditions in many sandstone formations and reservoir settings are considered to be relatively low, such that thermally activated deformation mechanisms (including intracrystalline plasticity and diffusive mass transfer) probably did not play important roles in the overall deformation and failure processes (Jamison and Stearns, 1982). When subjected to an overall compressive loading, the porous sandstone may fail by shear localization or by cataclastic flow.

Laboratory studies in the past decade have provided important insight into the phenomenology and micromechanics of the brittle-ductile transition in sandstones of different porosity, grain size, cementation and clay content.
Under a relatively low effective pressure, the application of a deviatoric stress field induces a porous sandstone to dilate and ultimately fail by brittle faulting. In contrast, the cataclastic deformation is delocalized when the porous rock is triaxially compressed under a relatively high effective pressure. This failure mode is usually associated with appreciable porosity decrease while the rock strain hardens (Edmond and Paterson, 1972; Jamison and Teufel, 1979). The yield stress for such compactive cataclastic flow decreases with increasing effective pressure (Wong et al., 1992).

It is of importance to distinguish between the mechanical responses to hydrostatic and nonhydrostatic loading. While compaction always arises from hydrostatic loading, whether porosity decreases or increases in response to a deviatoric stress field hinges on the trade-off between pore collapse mechanisms and the counteracting tendency for microcracking to dilate the sample. Compaction may persist over large strain only if damage is accumulated in a distributed manner. This in turn implies that the increasing number of microcracks somehow fail to coalesce, and thereby inhibit the onset of shear localization.

Figure 1 illustrates the hydrostatic compaction behavior for seven sandstones with porosities ranging from $14 \%$ to 35\% (Zhang et al., 1990a; David et al., 1994; Wong et al., 1997). The samples were all saturated with distilled water and compressed under drained conditions at a constant pore pressure of $10 \mathrm{MPa}$. Typically the mechanical response of a porous sandstone is nonlinear even for the elastic regime.

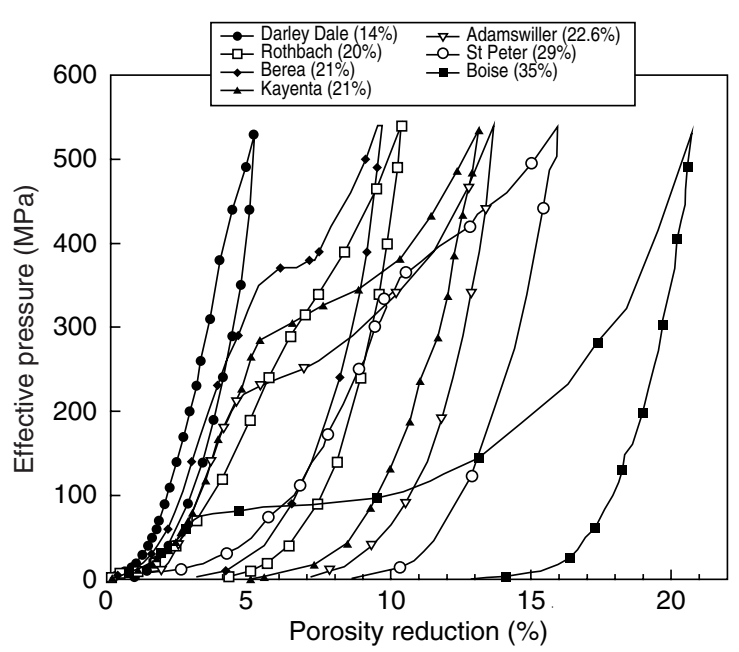

Figure 1

Hydrostats of seven sandstones. Each of the hydrostats show a sharp inflection point which corresponds to the critical effective pressure $P^{*}$ for the onset of grain crushing and pore collapse. The experiments were conducted on samples saturated with distilled water and under drained conditions. The nominal porosity of each sandstone is also indicated in bracket. 
Under hydrostatic loading, the pore space is initially tightened by elastic deformation, and as a result, it becomes more and more stiff. However, as the hydrostatic loading is increased further, a point is reached when the sample suddenly becomes more compliant, showing a dramatic increase in compaction. If a sample is loaded to beyond this inflection point and then unloaded, the permanent compaction is significant. This inflection point $P^{*}$ occurs at wide range of pressures, ranging from $80 \mathrm{MPa}$ to $400 \mathrm{MPa}$.

The inflection point in the hydrostatic compaction curve is manifested in the microstructure by the onset of grain crushing (Zhang et al., 1990a; Menéndez et al., 1996). The local stresses at impinging grain contacts are sufficiently high that extensile microcracks nucleate and propagate across the grains, manifested by marked enhancement of acoustic emission (AE) activity (Zhang et al., 1990b; David et al., 1994). The grains are crushed and the pores collapse, resulting in an overall decrease in porosity.

Noting that the magnitude of $P^{*}$ is primarily controlled by the porosity $\Phi$ and grain size $R$, Zhang et al. (1990a) formulated a Hertzian fracture model, in which the porous rock is idealized as a randomly packed assemblage of spherical particles of several distinct sizes. Under hydrostatic loading, the neighboring grains are in normal contact and tensile stress concentration is induced in the vicinity of the circle of contact between two impinging grains (Johnson, 1985). The maximum tensile stress is attained at the perimeter of the contact area, and the stress intensity factor $K_{I}$ of a preexisting flaw located at the contact region is approximated by that of an edge crack (Wilshaw, 1971). Hertzian fracture can initiate at the critical pressure $P^{*}$ if $K_{I}$ at a local contact reaches a critical value given by the fracture toughness $K_{I C}$. This micromechanical model for grain crushing predicts that:

$$
P *=\frac{2.2\left(1-v^{2}\right)^{2}}{E^{2}(1-2 v)^{3}} \frac{K_{I C}^{3}}{(\alpha \Phi R)^{3 / 2}}
$$

where $E$ is the Young's modulus, $v$ is the Poisson's ratio, and $\alpha$ is the ratio of the initial crack length to grain radius.

If one makes the plausible assumption that the preexisting flaw dimension scales as the grain dimension $R$, then this initiation condition (1) would imply that the critical pressure $P^{*}$ scales with the porosity and grain radius in accordance with $P^{*} \propto(\Phi R)^{-3 / 2}$. A compilation of the grain crushing pressure $P^{*}$ as a function of initial porosity $\Phi$ and grain radius $R$ is presented in Figure 2 (Wong et al., 1997). Other than experimental data for the porous siliciclastic rocks, we have also included data for unconsolidated materials (including sand and glass spheres). The mechanical data are in reasonable agreement with this theoretical prediction, with values of $\alpha$ on the order of $10^{-4}$.

To illustrate the responses to nonhydrostatic loading, a complete set of mechanical data for Adamswiller sandstone are shown in Figure 3. The top graph shows the differential stress $\sigma_{1}-\sigma_{3}$ versus the axial strain for six triaxial compression experiments at a fixed pore pressure of $10 \mathrm{MPa}$ and with confining pressures maintained at 15, 30, 50, 70,

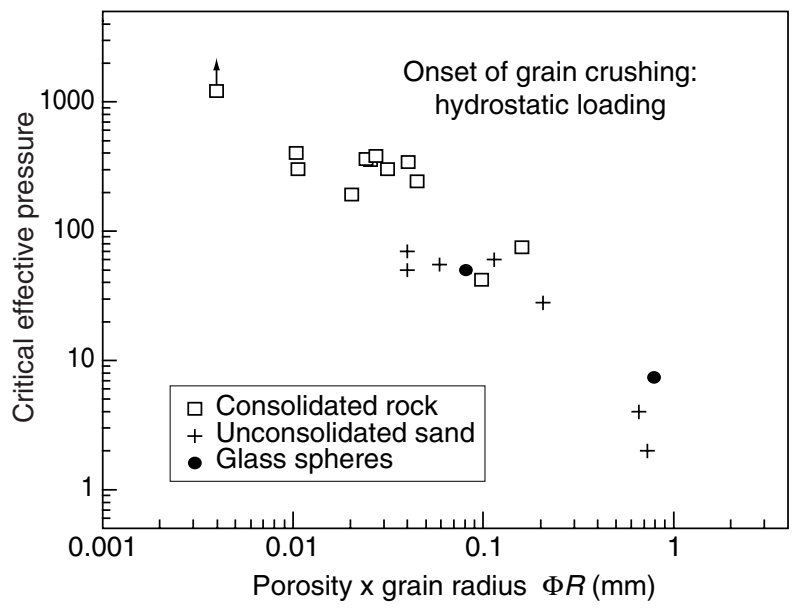

Figure 2

Critical effective pressure for the onset of grain crushing under hydrostatic loading $\left(P^{*}\right)$ as a function of initial porosity and grain radius. The data follow an approximately linear trend with a slope of $-3 / 2$, in accordance with Equation (1).

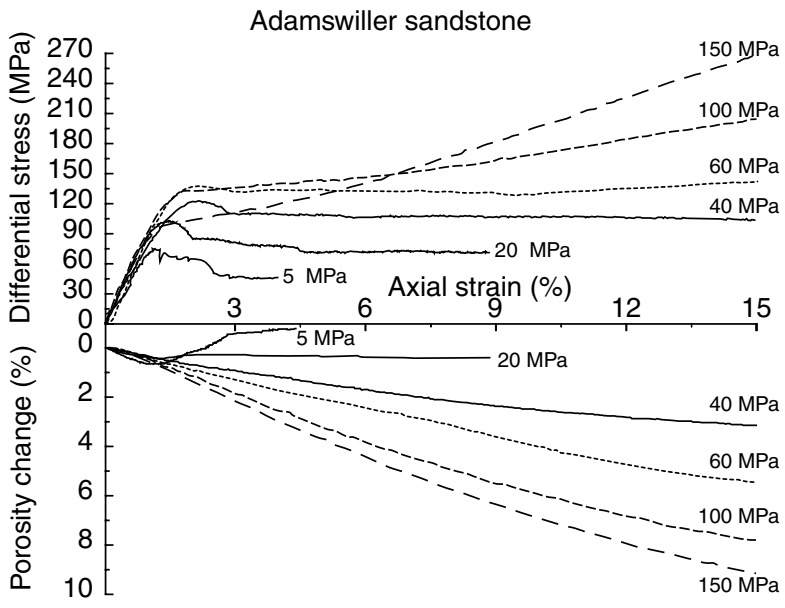

Figure 3

Mechanical data for saturated Adamswiller sandstone. Differential stress and porosity change were plotted versus axial strain. Effective pressures were as indicated. The solid curves are for samples which failed by shear localization, and the dashed curves are for samples which failed by cataclastic flow, with delocalized compaction and strain hardening. 
110 and $160 \mathrm{MPa}$, respectively. The bottom graph shows porosity decrease versus axial strain for the same samples.

The samples deformed at an effective pressures of $5 \mathrm{MPa}$ and $20 \mathrm{MPa}$ are representative of the brittle faulting regime. The differential stress attained a peak, beyond which strain softening was observed and the stress progressively dropped to a residual level. The peak stress shows a positive correlation with effective pressure, which is typical of MohrCoulomb type of brittle failure. The porosity initially decreased, but near the peak stress it reversed to an increase indicating dilation of the pore space. The dilation decreased with increasing effective pressure. Visual inspection of post-peak samples confirmed that they failed by shear localization, with a thoroughgoing shear band cutting across each sample.

The dashed curves (for samples deformed at effective pressures of 60,100 and $150 \mathrm{MPa}$ ) are representative of the compactive cataclastic flow regime. The slopes of the differential stress-axial strain curve were nonnegative, and the porosity decreased monotonically with deformation. Shear localization was not evident in samples deformed to an axial strain of up to $30 \%$. The sample deformed at $40 \mathrm{MPa}$ showed a peak stress and strain softening, but the porosity persistently decreased with deformation. This "transitional" mode of failure is manifested by the development of several conjugate shear bands in the sample.

Additional insights are gained by plotting the effective mean stress $\left(\sigma_{1}+2 \sigma_{3}\right) / 3-P_{p}$ versus the porosity change (Figs. $4 \mathrm{a}$ and $4 \mathrm{~b}$ ). For reference, the hydrostat is also shown (as the dashed curves). In a triaxial compression experiment, the nonhydrostatic and hydrostatic loadings are coupled together. If the porosity change is solely controlled by the hydrostatic stresses, then the triaxial data (solid curves) should coincide with the hydrostat (dashed curves) in Figure 4. Deviations from the hydrostat would imply that additional porosity change was induced by the deviatoric stresses. In the cataclastic flow regime, the triaxial curve for a given effective pressure coincided with the hydrostat up to a critical stress state (indicated by $C^{*}$ in Figure $4 \mathrm{~b}$ ), beyond which there was an accelerated decrease in porosity in comparison to the hydrostat. At stress levels beyond $C^{*}$ the deviatoric stress field provided significant contribution to the compactive strain, and this phenomenon is referred to as "shear-enhanced compaction" (Curran and Carroll, 1979; Wong et al., 1992). In contrast, the porosity change behavior at effective pressures of 5 and $20 \mathrm{MPa}$ was such that the compaction decelerated in comparison to the hydrostat beyond critical stress states marked as $C^{\prime}$ (Fig. 4a). This implies that at stress levels beyond $C$ ' the deviatoric stress field induced the pore space to dilate.

The critical stress levels for the onset of shear-enhanced compaction varies significantly among sandstones. Data for six sandstone with porosities ranging from $15 \%$ to $35 \%$ (from Wong et al., 1997) are shown in Figure 5 in the stress space, with coordinates given by the effective mean stress $P\left(=\left(\sigma_{1}+2 \sigma_{3}\right) / 3-P_{p}\right)$ and the differential stress $Q\left(=\sigma_{1}\right.$ $-\sigma_{3}$ ). For reference, the Mohr-Coulomb peak stresses (for brittle fracture under relatively low effective pressures) are also included as solid symbols. The $C^{*}$ data (open symbols) map out the compactive yield envelopes for the onset of
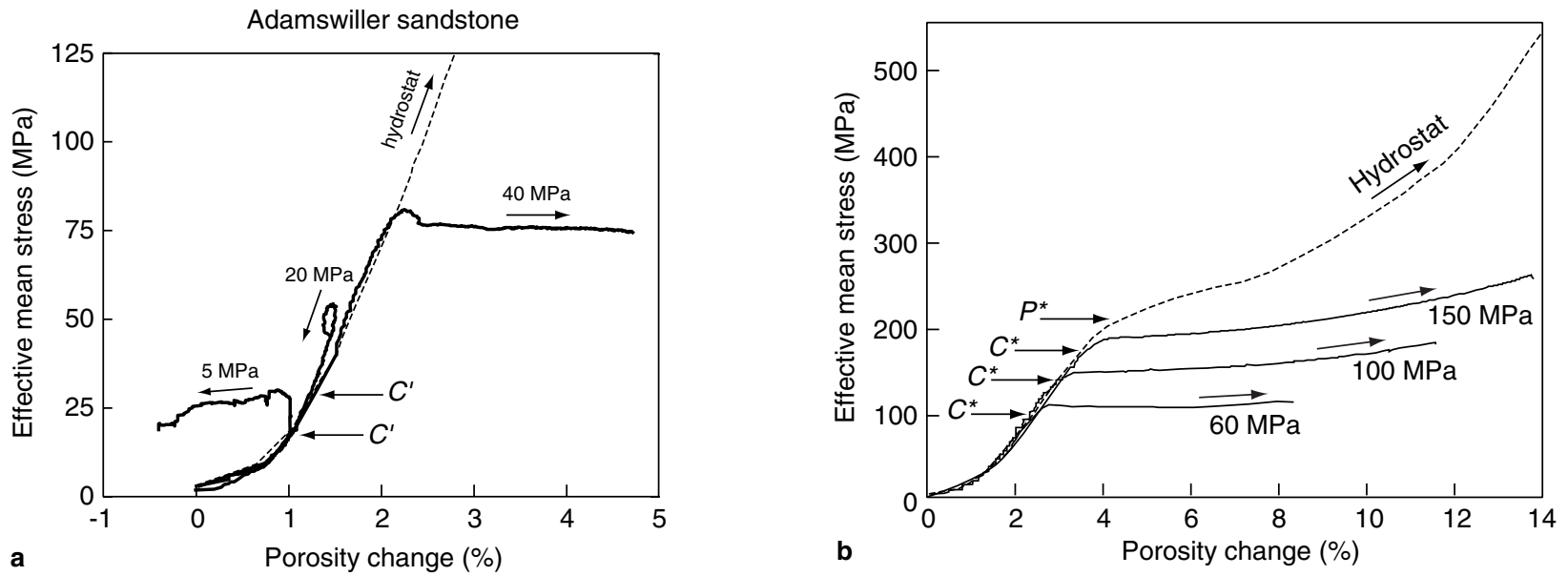

Figure 4

(a) Shear-induced dilation and (b) compaction in saturated Adamswiller sandstone. The solid curves show the effective mean stress as a function of porosity change for triaxial compression tests at fixed effective pressures as indicated. For reference the hydrostat is shown as dashed curves. The critical stress states $C^{\prime}$ and $C^{*}$ are indicated by the arrows. 


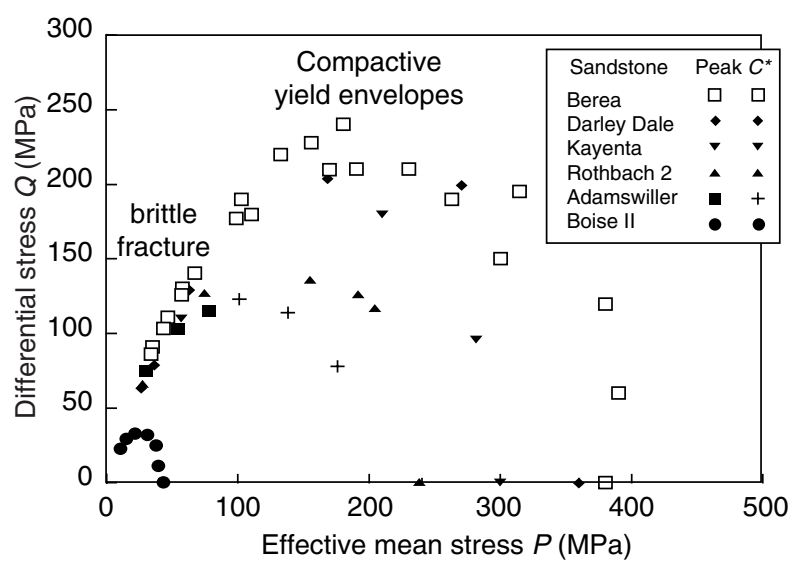

Figure 5

Stress state $C^{*}$ at the onset of shear-enhanced compaction (open symbols) and peak stress for brittle fracture (solid symbols) are shown in the $P$ (effective mean stress) and $Q$ (differential stress) space. Note that the compactive yield envelopes have approximately elliptical shapes with negative slopes. Data for six saturated sandstones are shown.

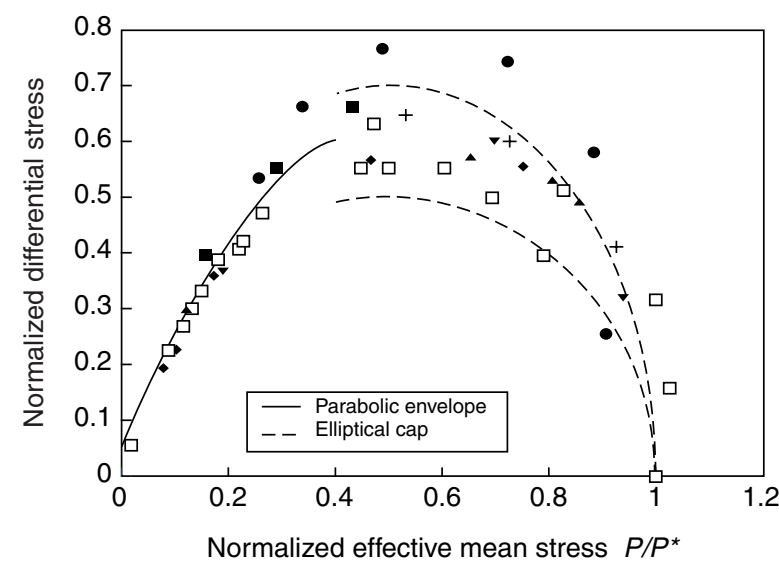

Figure 6

Stress state $C^{*}$ at the onset of shear-enhanced compaction (open symbols) and peak stress for brittle fracture (solids symbols) of saturated sandstone are shown in the normalized $P-Q$ space. Effective mean stress and differential stress are both normalized by the grain crushing pressure. Most of the $C^{*}$ data are bracketed by the two elliptical caps (dashed curves), corresponding to $(2)$ with $(\gamma, \delta)=(0.5,0.5)$ and $(0.5,0.7)$, respectively. The peak stress data are fitted with a parabolic fracture envelope (solid curve) (Wong et al., 1997). Keys are as in Figure 5.slopes. Data for six saturated sandstones are shown. shear-enhanced compaction, that is manifested by a negative correlation between $P$ and $Q$ at the critical stress states. The data underscore that shear-enhanced compaction and cataclastic flow can occur over a broad range of stress conditions. The compactive yield envelope of Berea sandstone has stress values more than 5 times those of Boise sandstone. Since the former has a porosity of $21 \%$ and the latter $35 \%$, one may infer that porosity exerts important influence over the compactive yield behavior. However, other microstructural parameters (such as grain size, cementation and clay content) may also be important since there is considerable discrepancy between the yield envelopes of Berea and Kayenta sandstones, both of which have porosity of $21 \%$.

Since one end of the compactive yield envelope is "anchored" at a location of the $P$ axis corresponding to $P^{*}$, this implies that if a rock requires a relatively high effective pressure for grain crushing to occur, then the critical stress states for the onset of shear-enhanced compaction are also expected to be high. In other words, the grain crushing pressure $P^{*}$ acts as a scaling parameter for the magnitudes of the compactive yield stresses $C^{*}$. This is illustrated by plotting the six yield envelopes from Figure 5 in the normalized stress space, with coordinates in $P / P^{*}$ and $Q / P^{*}$ (Fig. 6). In this sense the critical pressure $P^{*}$ provides a quantitative measure of the "brittleness" of a porous siliciclastic rock.
The negative pressure dependence of the compactive yield envelope has been widely observed in soil mechanics (Chen, 1984; Desai and Siriwardane, 1984). Therefore soil plasticity formulations such as the critical state (Schofield and Wroth, 1968) and cap (DiMaggio and Sandler, 1971) models can provide a constitutive framework for the analysis of cataclastic flow. In critical state soil mechanics, both circular and elliptical loci in the $P-Q$ space have been proposed for the initial yield envelope. For soil it is commonly assumed that the yield locus passes through the origin, but this restriction can be relaxed for cemented materials (Wood, 1990). In the cap model an elliptical cap is commonly adopted (DiMaggio and Sandler, 1971). As shown in Figure 6, most of the porous sandstone data are bracketed by the elliptical loci (dashed curves) given by:

$$
\frac{(P / P *-\xi)^{2}}{(1-\xi)^{2}}+\frac{\left(Q / P^{*}\right)^{2}}{\delta^{2}}=1
$$

with peaks at $(\xi, \delta)=(0.5,0.5)$ and $(0.5,0.7)$, respectively. Since microstructural parameters (such as porosity and grain size) exert control over the hydrostatic grain crushing process in accordance with Equation(1), they should similarly influence the compactive yield envelope since the stress invariants in Equation (2) are normalized with respect to $P^{*}$. The yield envelope for onset of shear-enhanced compaction expands with decreasing porosity and grain size. 


\section{STRAIN HARDENING AND SPATIAL EVOLUTION OF DAMAGE}

In plasticity theory the conventional approach is to associate a flow rule with the yield envelope. An elliptical cap given by Equation (2) for axisymmetric loading corresponds to the following yield function in the general stress space:

$$
f\left(\sigma_{i j}\right)=\frac{\left(I_{1}-c\right)^{2}}{a^{2}}+\frac{J_{2}}{b^{2}}-1=0
$$

with:

$$
\begin{aligned}
& a=3(1-\xi) P^{*}, \\
& b=\delta / \sqrt{3} P^{*}, \\
& c=3 \xi P^{*}
\end{aligned}
$$

and the first and second stress invariants are:

$$
I_{1}=\left(\sigma_{11}-P_{p}\right)+\left(\sigma_{22}-P_{P}\right)+\left(\sigma_{33}-P_{P}\right)
$$$$
\text { and } J_{2}=\left[\left(\sigma_{11}-\sigma_{22}\right)^{2}+\left(\sigma_{22}-\sigma_{33}\right)^{2}+\left(\sigma_{33}-\sigma_{11}\right)^{2}\right] / 6
$$

$$
+\sigma_{12}^{2}+\sigma_{23}^{2}+\sigma_{13}^{2} \text {. }
$$

At the onset of shear-enhanced compaction, if the inelastic deformation follows Drucker's (1951) postulate of material stability, then the following "normality" condition applies:

$$
\Delta \varepsilon_{i j}^{p}=\frac{\partial f}{\partial \sigma_{i j}} \Delta \lambda
$$

where $\Delta \varepsilon^{p}{ }_{i j}$ denotes the plastic increment of the strain tensor and $\Delta \lambda$ is a positive scalar. Specifically for axisymmetric loading we define the "inelastic compaction factor" $\Delta \Phi^{p} / \Delta \varepsilon^{p}$ to be the ratio between incremental changes of plastic components of the porosity and axial strain. Substituting the yield function (3a) into (3b) gives the "inelastic compaction factor" (Wong et al., 1997):

$$
\frac{\Delta \Phi^{p}}{\Delta \varepsilon^{p}}=3 \frac{3}{1+[\delta /(1-\xi)]^{2}\left[\left(P-\xi P^{*}\right) /(3 Q)\right]}
$$

The theoretical predictions for the compaction factor as a function of the effective pressure $P_{c}-P_{p}$ (normalized by the crushing pressure $P^{*}$ ) are shown as dashed curves in Figure 7. They are associated with the two elliptical caps shown in Figure 6. For hydrostatic loading the compaction factor attains its maximum value of 3 when the effective pressure equals the critical crushing pressure $P^{*}$. At a lower effective pressure, a differential stress $(Q>0)$ is necessary for the onset of shear-enhanced compaction, and the normality condition requires a compaction factor which is significantly lower than 3 . The laboratory data are comparable in magnitude to the theoretical prediction for effective pressures down to $0.5 P^{*}$ or so (Fig. 7). Previous studies on carbonate rocks (Elliott and Brown, 1985) and saline ice (Schulson and Nickolayev, 1995) indicate similar agreement between experiment and theory.

While the experimental measurements of inelastic compaction are comparable to the predictions of the associative flow rule and normality condition for effective pressures ranging

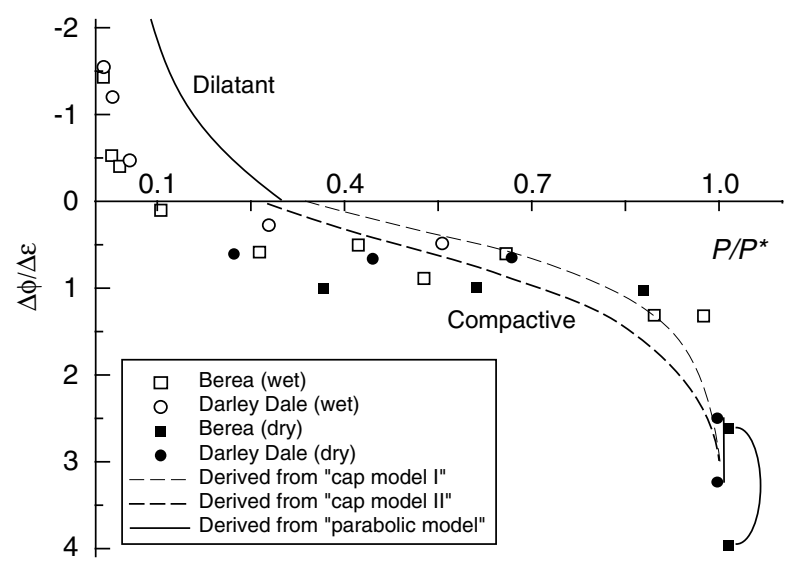

Figure 7

Inelastic compaction factor as function of effective pressure (normalized by the grain crushing pressure) for nominally dry and saturated sandstone. Experimental data are compared with theoretical predictions of plasticity models assuming normality. The dashed curves are calculated from the associated flow rule for the two elliptical (compactive yield) caps in Figure 6. The solid curve is from the associated flow rule for the parabolic envelope (for brittle fracture) in Figure 6. Data points connected by lines are from hydrostatic experiments on nominally dry samples-the strain measurements in orthogonal directions were different due to pre-existing anisotropy in the sandstones.

from $\sim 0.5 P^{*}$ to $P^{*}$, appreciable discrepancy exists at lower pressures. We have also plotted in Figure 7 the theoretical predictions at relatively low pressures at which the samples failed by brittle faulting. The normality condition requires the inelastic compaction factor to be negative in this regime, at effective pressures ranging from 0 to $\left(p_{o}-q_{o} / 3\right) P^{*}$. While the laboratory data do indicate dilatancy and therefore agree qualitatively with the theory, there is significant discrepancy between the magnitudes of the theoretically predicted and experimental values. This tendency for an associated flow rule to consistently overestimate the magnitude of dilatation at brittle failure has previously been noted in soil (Chen, 1984; Desai and Siriwardane, 1984) and in low-porosity rock (Senseny et al., 1983).

It should also be noted that both specific predictions of plasticity theory on the strain hardening and compaction behavior have not been tested quantitatively. For Berea sandstone, Wong et al. (1992) showed that during cataclastic flow the yield envelope expands as a function of decreasing porosity (Fig. 8), in qualitative agreement with a plasticity model that uses porosity as the hardening parameter. Nevertheless, quantitative comparison with the theoretical predictions would require detailed measurements of stress, strain and porosity changes during cyclic loading to "probe" the expanding yield envelope. It is desirable to pursue a systematic study of this question in the future. 


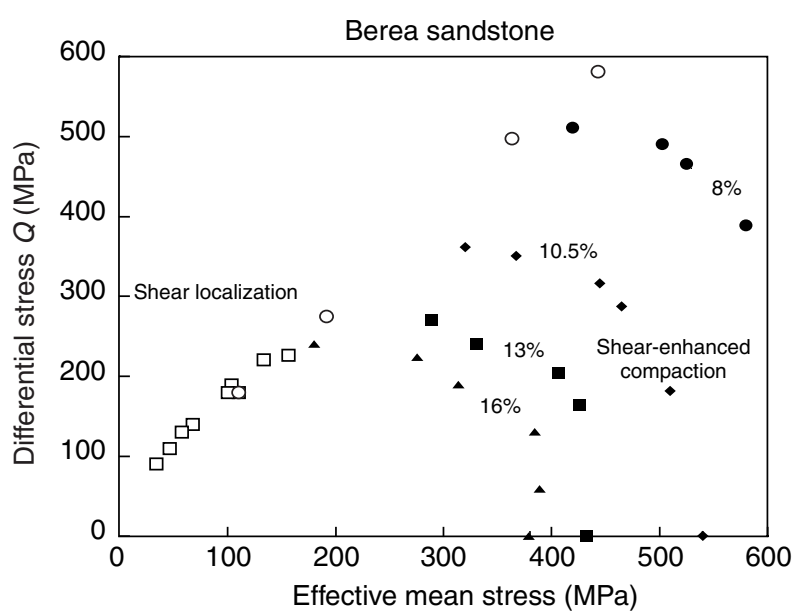

Figure 8

Loci for brittle failure by shear localization and for inelastic yield by shear-enhanced compaction in the effective mean stress $(P)$ and differential stress $(Q)$ space for saturated Berea sandstone. After the onset of shear-enhanced compaction and grain crushing, the hardening stress states at fixed values of porosity are plotted to delineate the inelastic yield envelope (Wong et al., 1992). Data shown are for five triaxial compression experiments on normally consolidated samples at effective pressures of $100 \mathrm{MPa}, 200 \mathrm{MPa}, 250 \mathrm{MPa}$, $340 \mathrm{MPa}, 370 \mathrm{MPa}$ and $450 \mathrm{MPa}$. Note that the yield envelope expands with porosity reduction.

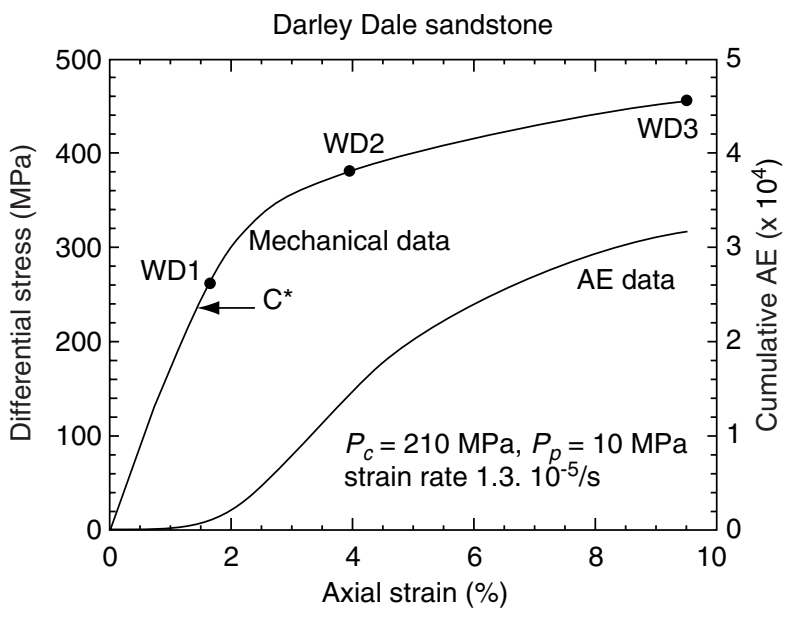

Figure 9

Principal stress difference $\sigma_{1}-\sigma_{3}$ versus axial strain for triaxially compressed samples of Darley Dale sandstone (WD1, WD2 and WD3) with indication of the peak stresses attained by the samples. Acoustic emission activity is indicated by the dashed curve. The experiments were conducted on saturated samples at confining pressure, pore pressure and strain rate as indicated.
While mechanical measurements are phenomenological attributes, acoustic emission (AE) and microstructural observations provide important insights into the spatial and temporal evolution of grain-scale damage during mechanical compaction. Representative data (from an experiment on Darley Dale sandstone deformed at an effective pressure of $200 \mathrm{MPa}$ ) for AE activity versus axial strain and differential stress are presented in Figure 9. Typically the AE activity shows an accelerated increase near the compactive yield stress $C^{*}$ and peaked after the sample has undergone a certain amount of shear-enhanced compaction.

$\mathrm{AE}$ activity in rock is identified with damage processes, including microcracking, frictional slip, and pore collapse. Such damage processes in Berea and Darley Dale sandstones were documented by Menéndez et al. (1996) and Wu et al. (1999), respectively. Intragranular cracking dominates the hydrostatic and triaxial compaction processes. The surge in AE activity at the critical stress $C^{*}$ marks the onset of "Hertzian fractures" that emanate from impinging grain contacts due to local tensile stress concentrations. These intragranular cracks extend across the grains, resulting in comminution and pore collapse (Fig. 10).

To visualize the spatial evolution of damage in Darley Dale sandstone, Wu et al. (1999) subdivided the section of each deformed sample into 121 sub-regions, and used stereological techniques to characterize the crack intercept densities (in directions perpendicular and parallel to the axial direction) in each sub-region. The stereological data (for the samples WD1, WD2 and WD3 retrieved at different stages of deformation indicated in Figure 9) show that the overall damage increased progressively with the development of shear-enhanced compaction and strain hardening. The crack densities as functions of the axial strain follow approximately linear trends (Fig. 11). While the damage seems to become somewhat anisotropic and more clustered in the highly deformed samples, shear localization is absent even in the sample WD3 that has accumulated an axial strain of $9.5 \%$ (Fig. 12).

\section{WEAKENING EFFECT OF WATER ON MECHANICAL COMPACTION}

Aqueous pore fluid exerts significant mechanical and chemical effects on virtually all crustal processes. Previous studies have shown that brittle strength of a rock is generally reduced in the presence of water. The water-weakening effect may arise from two mechanisms. The mechanical role of pressurized pore fluid tends to weaken and embrittle rocks (Paterson, 1978), and the chemical influence of pore fluids is to further weaken the rock through a reduction of surface free energy (Rehbinder et al., 1948; Orowan, 1944), a subcritical 

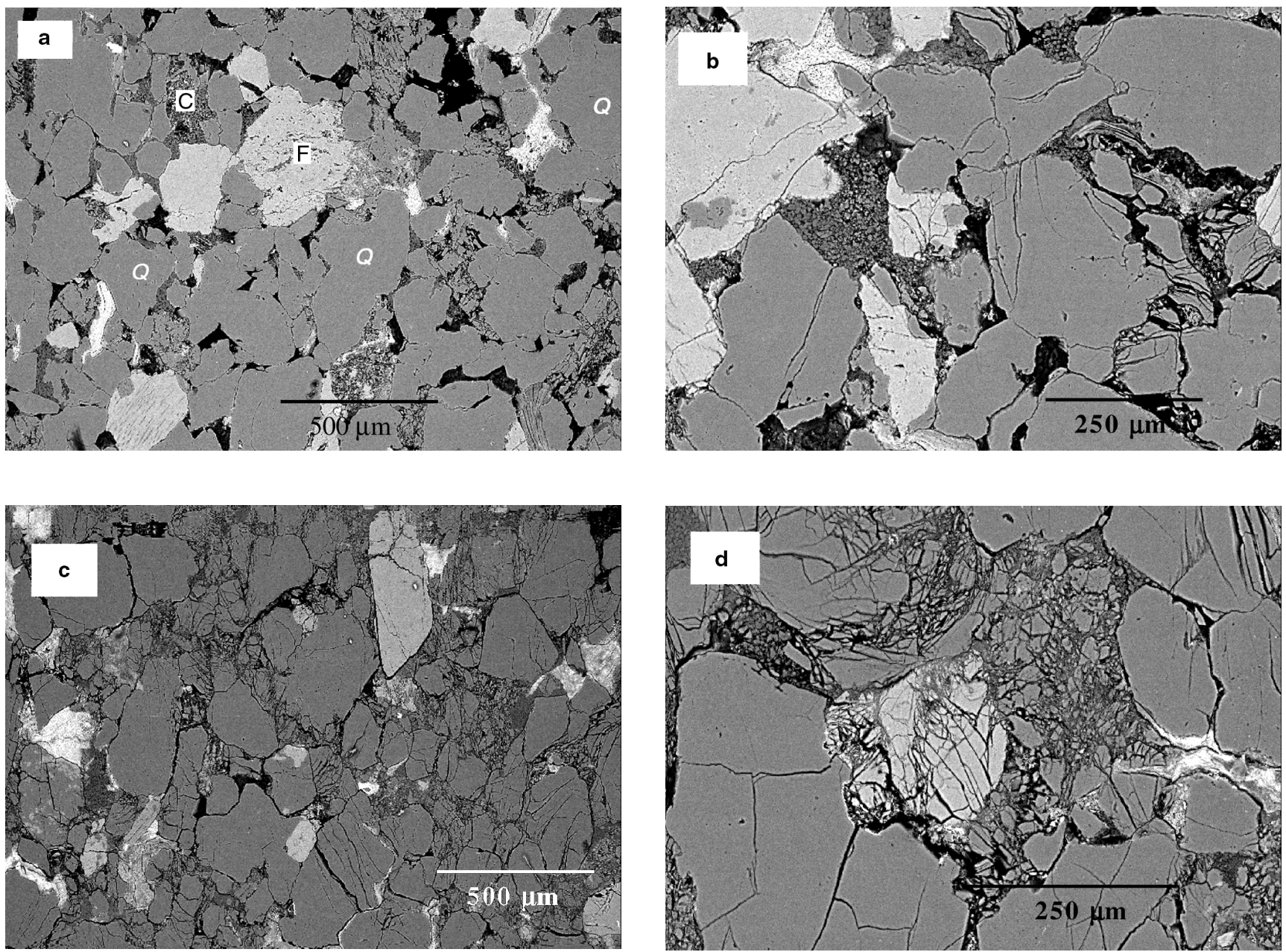

Figure 10

Scanning electron micrographs of unstressed and deformed samples of Darley Dale sandstone. (a) In an unstressed sample, the main mineralogical components are indicated: quartz $(Q)$, clay $(C)$ and feldspar $(F)$. (b) Onset of grain crushing observed in sample WD1 that was triaxially compacted to just beyond the critical stress $C^{*}$. (c) Extensive development of grain crushing and pore collapse as observed in the sample WD3 under relatively low magnification. (d) Details of (c) revealed at higher magnification. The $\sigma_{1}$ direction is vertical in these micrographs.

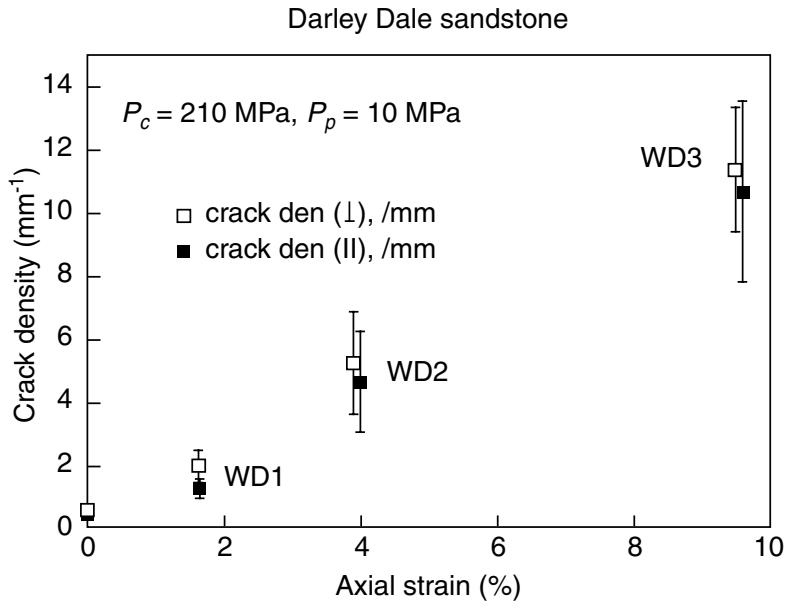

Figure 11

Mean crack intercept densities measured in directions perpendicular and parallel to the $\sigma_{1}$ direction. Data for the WD-series (Fig. 9) are plotted as functions of the axial strain. The standard deviations are shown as error bars. 

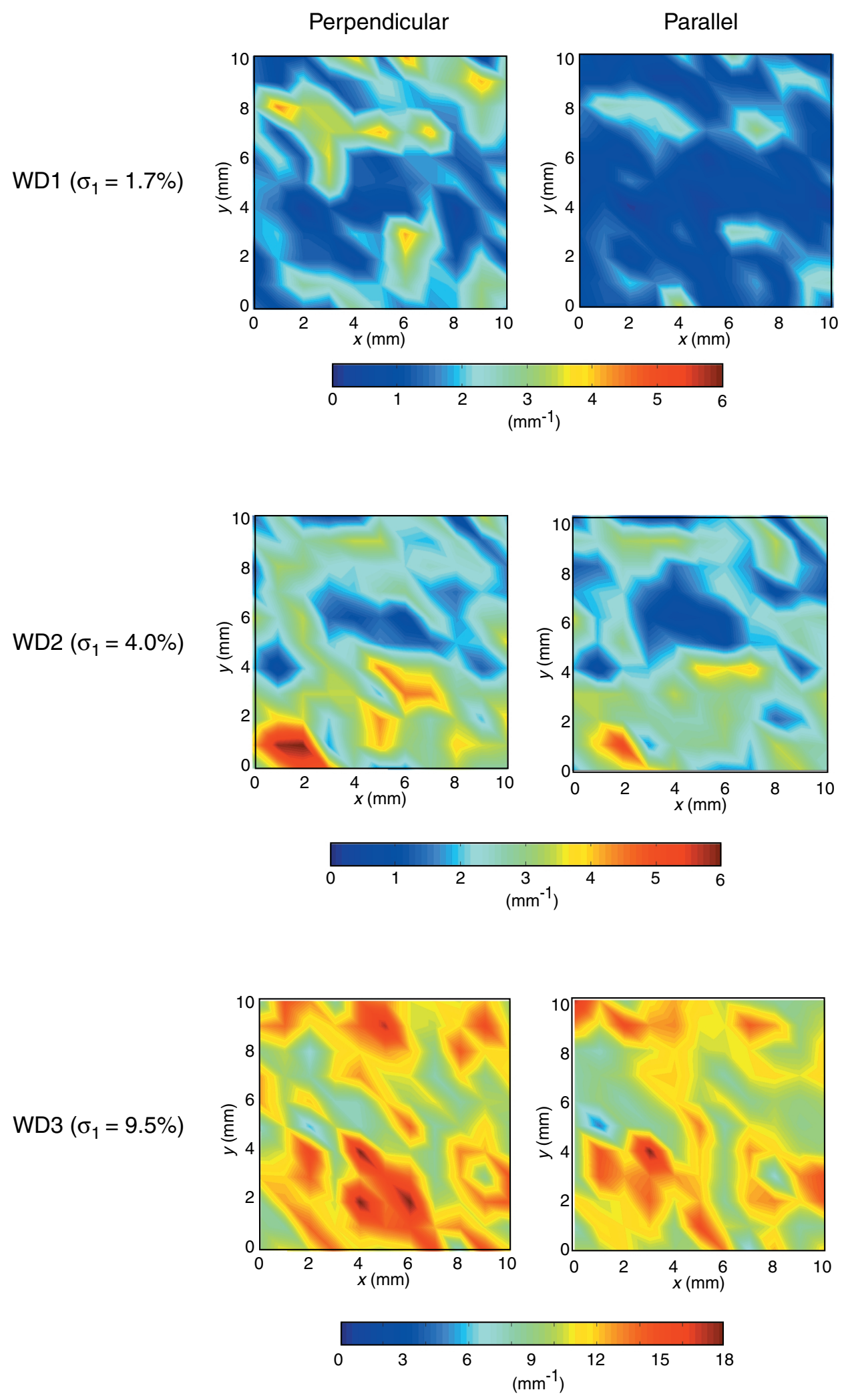

Figure 12

Spatial distribution of crack intercept densities measured in directions perpendicular and parallel to the $\sigma_{1}$ direction in the WD-series. 
cracking mechanism such as stress corrosion (Atkinson and Meredith, 1987), or both combined.

Unlike the brittle faulting regime, there is a paucity of data on the water-weakening behavior during compaction and strain hardening. Stress-strain data on Berea sandstone reported by Handin et al. (1963) and Bernabé and Brace (1990) suggest a very slight weakening effect in the watersaturated samples. In contrast, Read et al. (1995) and Zhu and Wong (1997a) recently presented data from one experiment on Darley Dale that showed very significant weakening. To elucidate the weakening effect of water in the compactive cataclastic flow regime, Baud et al. (1999) recently conducted a series of triaxial compression experiments on the Berea, Boise, Darley Dale, and Gosford sandstones (with nominal porosities ranging from $11 \%$ to $35 \%$ ) under nominally dry and saturated conditions at room temperature.

As illustrated in Figure 13 (for Darley Dale sandstone at effective pressures ranging from $10 \mathrm{MPa}$ to $300 \mathrm{MPa}$ ), the inelastic behavior and failure mode of nominal dry samples were qualitatively similar to those of water saturated samples. At elevated pressures shear localization was inhibited and all the samples failed by strain hardening. The compactive yield strengths (associated with the onset of shear-enhanced compaction) of the nominally dry and saturated samples are compiled in Figure 14. It can be seen that the latter were lower than those in the dry samples deformed under comparable pressure conditions by $20 \%$ to $70 \%$. The waterweakening effects were most and least significant in the Gosford and Berea sandstones, respectively.

The yield stresses at the onset of shear-enhanced compaction for the nominally dry samples can also be described by elliptical envelopes (Eq. (2)) (Zhu and Wong, 1997a; Baud et al., 1999). If the inelastic compaction factors were evaluated according to Equation (3c) assuming the associated flow and normality condition, then the laboratory data for the nominally dry samples are comparable in magnitude to the theoretical prediction for effective pressures down to $0.5 P^{*}$ or so (Fig. 6).

The Hertzian fracture model can be modified to account for the water-weakening effect. According to the Griffith (1920) theory, the mechanics of fracture in an ideally brittle solid is governed by the specific surface energy $\gamma$, such that equilibrium propagation of a crack occurs if the strain energy release rate $G$ attains the critical value (also called the fracture energy) $G_{c}=2 \gamma$. Equivalently, this condition can be expressed in terms of the stress intensity factors (Irwin, 1958). In an elastic solid (with Young's modulus $E$ and Poisson's ratio $v$ ), extensile crack growth (in plane strain condition) occurs if the stress intensity factor $K_{I}$ attains the critical value such that $K_{I C}$ such that:

$$
G_{c}=\frac{\left(1-v^{2}\right)}{E} \mathrm{~K}_{I C}^{2}=2 \gamma
$$

One of the earliest theories of chemistry in brittle fracture was that of Orowan (1944), who proposed that the environmental molecules lower the interface energy on entering the crack interface and adsorbing onto the walls in the cohesion/adhesion zone. While the decohesion of a solid body in vacuo is characterized by the specific surface energy $\gamma$, the separation of two solid half-bodies in a fluid environment is characterized by the solid-fluid interface energy $\gamma$ '. For the environmentally susceptible system, equilibrium propagation of a tensile crack occurs if the strain energy release rate (or stress intensity factor) attains the critical value $\mathrm{G}_{c}{ }_{c}\left(\right.$ or $\left.K^{\prime}{ }_{I C}\right)$ such that:

$$
G_{c}^{\prime}=\frac{\left(1-v^{2}\right)}{E} K_{I C}^{\prime 2}=2 \gamma^{\prime}
$$

If $\gamma^{\prime}<\gamma$, then adsorption occurs and the cohesion of the solid is lowered by the environmental interaction, with corresponding reduction in strength that is related to the ratio:

$$
\lambda=\gamma^{\prime} / \gamma=\left(\mathrm{K}_{I C}^{\prime} / K_{I C}\right)^{2}
$$

In Equation (1), since environmental interaction is not expected to have insignificant impact on the elastic moduli, initial crack length or porosity, the critical pressure $P_{\text {wet }}^{*}$ in a saturated sample is expected to have a lower value that arises primarily from environmentally induced reduction of the fracture toughness. This implies that in the Hertzian fracture model the water-weakening effect on grain crushing is related to the ratio $\lambda$ in the following manner (Baud et al., 1999):

$$
\frac{P_{w e t}^{*}}{P_{d r y}^{*}}=\left(\frac{K_{I C}^{\prime}}{K_{I C}}\right)^{3}=\left(\frac{\gamma^{\prime}}{\gamma}\right)^{3 / 2}=\lambda^{3 / 2}
$$

Using this approach, hydrostatic data on grain crushing pressures of dry and wet samples can be used to infer $\lambda$ (Table 1). Our analysis shows that the water-weakening effect in the cataclastic flow regime can be explained by comparable values of $\lambda$ (that range from 0.83 to 0.89 ) in the Darley Dale, Gosford and Boise sandstones, while the

\section{TABLE 1}

Compilation of the elliptical yield envelope parameters ( $\xi$ and $\delta$ in Eq. (2)) and parameter $\lambda$ (inferred from Eq. (5)) for nominally dry and saturated sandstone samples deformed in the compactive cataclastic flow regime (from Baud et al., 1999)

\begin{tabular}{l|c|c|c|c|c|c}
\hline Sandstone & $\begin{array}{c}\text { Porosity } \\
\phi(\%)\end{array}$ & $\begin{array}{c}\xi \\
(\mathrm{dry})\end{array}$ & $\begin{array}{c}\delta \\
(\mathrm{dry})\end{array}$ & $\begin{array}{c}\xi \\
(\text { wet })\end{array}$ & $\begin{array}{c}\delta \\
(\text { wet })\end{array}$ & $\lambda$ \\
\hline Gosford & 10.5 & 0.6 & 0.74 & 0.57 & 0.53 & 0.83 \\
\hline Darley Dale & 13 & 0.61 & 0.74 & 0.57 & 0.74 & 0.87 \\
\hline Berea & 21 & 0.57 & 0.52 & 0.55 & 0.51 & 0.97 \\
\hline Boise & 35 & 0.55 & 0.85 & 0.55 & 0.72 & 0.79 \\
\hline
\end{tabular}



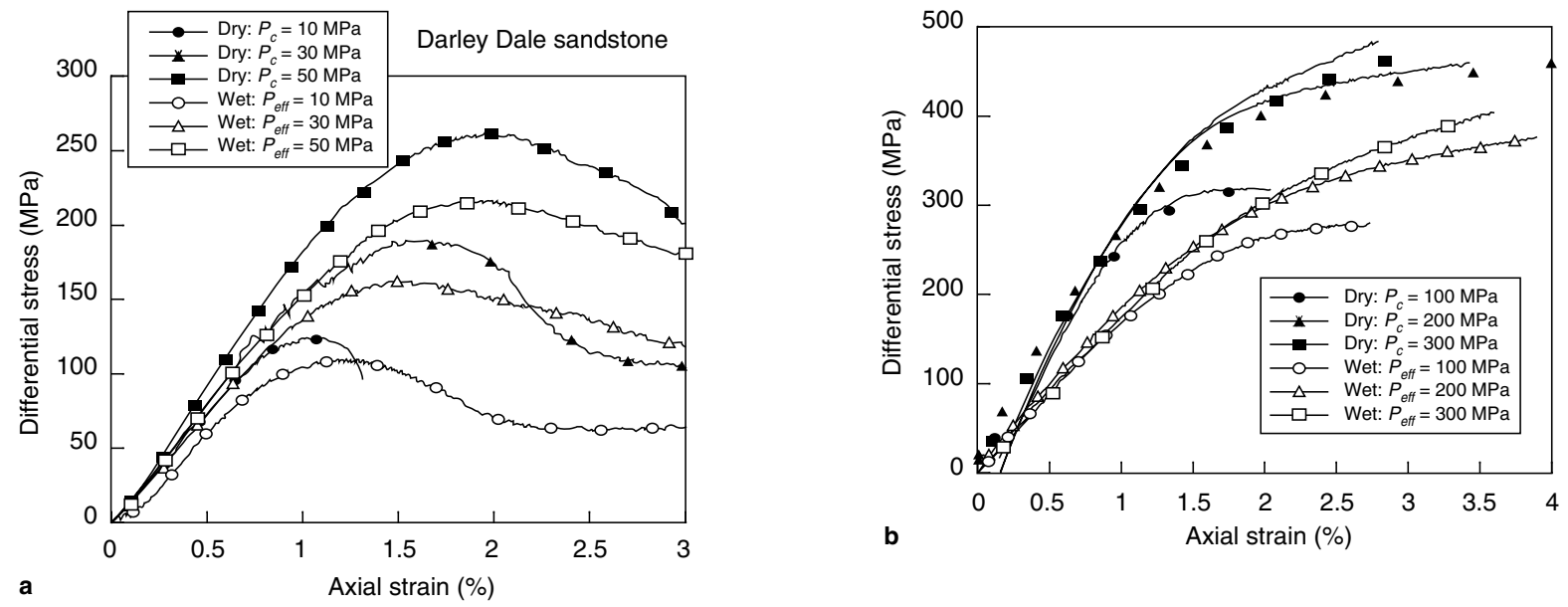

Figure 13

Mechanical data for Darley Dale sandstone for samples deformed in the brittle regime (a) and in the cataclastic flow regime (b). Differential stress and porosity change were plotted versus axial strain. The open symbols are for water saturated samples and the closed symbols are for the nominally dry samples.
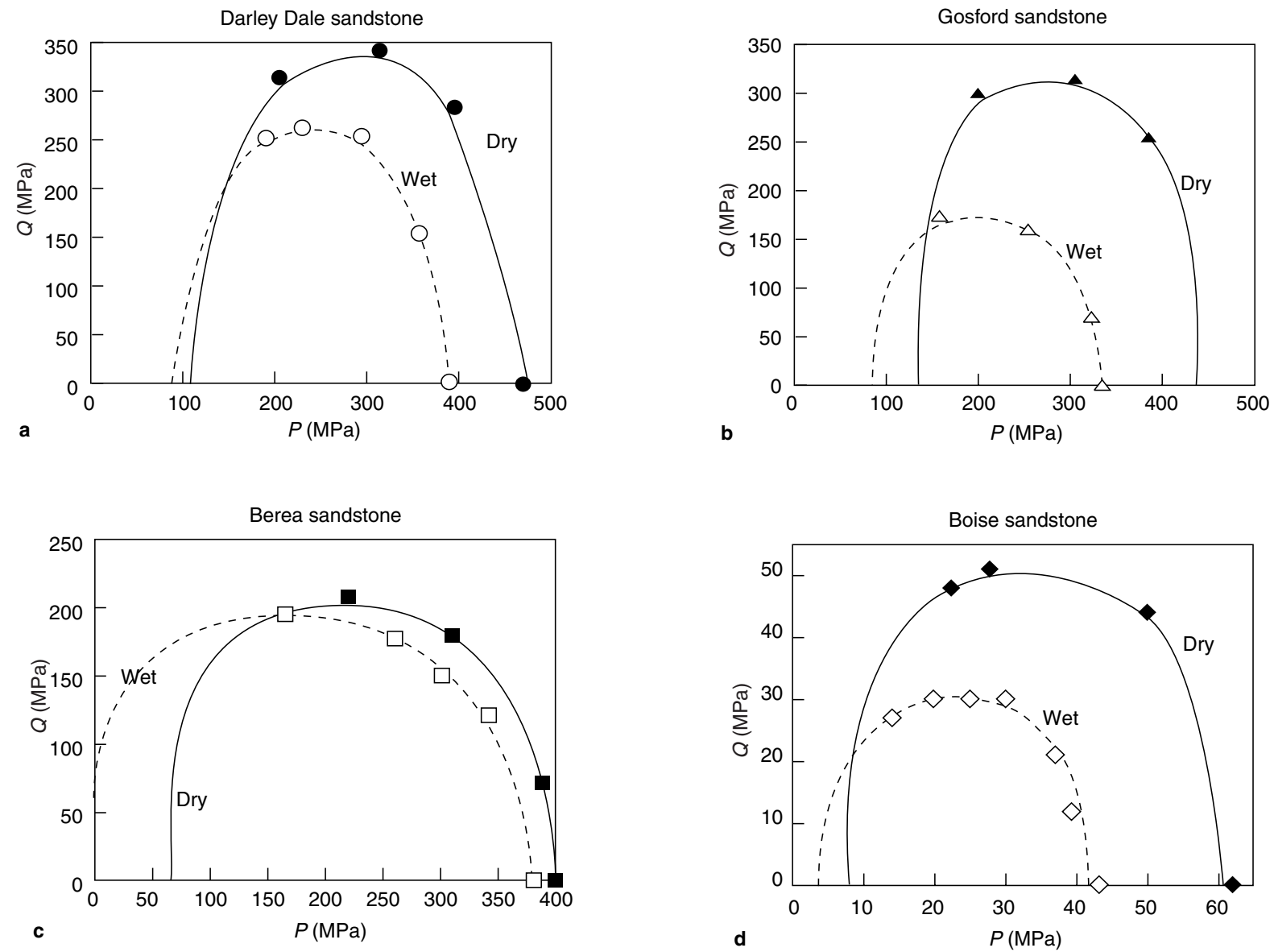

Figure 14

Elliptical envelopes that fit the initial yield envelopes of four sandstones in dry and wet conditions. The parameters of the envelopes are given in Table 1. 
water-weakening effect is almost negligible in Berea sandstone (with $\lambda=0.97$ ). These relatively small reductions in fracture energy due to the presence of water are in agreement with limited fracture mechanics data for silicate minerals and rocks (Atkinson and Meredith, 1987; Lajtai et al., 1987).

Baud et al. (1999) also show that Equations (1) and (5) together would imply that $P^{*} \propto[\lambda /(\phi R)]^{3 / 2}$, where the ratio $\lambda$ has a value of unity in vacuo, and a value less than one for a sandstone saturated with fluid. According to the above, an environmentally induced reduction of surface energy of $10 \%$ has the same consequence on the grain crushing pressure as an increase of the grain size by $10 \%$ (or comparable increase in porosity).

\section{DISCUSSION}

In this paper, we have reviewed recent experimental data on the phenomenology of mechanical compaction, microstructural characterization of the spatial evolution of damage, as well as the micromechanical modeling of these phenomena in porous sandstone. A methodology integrating these different approaches have provided useful insights into the physics and chemistry of mechanical compaction. On one hand, conventional concepts from plasticity theory provide first-order macroscopic description of the inelastic and failure behavior. On the other hand, linear elastic fracture mechanics and elastic contact mechanics provide are useful tools for analyzing the micromechanical behavior and chemical influence of water.

Although our review has focused on the failure mode and deformation regime in which the failure is delocalized and compactive, it should be noted that linear elastic fracture mechanics has also been used quite successfully to analyze the low-pressure failure mode that involves development of dilatancy and brittle faulting. For example, the "sliding wing crack" model (e.g. Horii and Nemat-Nasser, 1986; Ashby and Sammis, 1990; Kemeny and Cook, 1991) provides a relatively simple description of the micromechanics, with reasonable agreement with laboratory and microstructural data (e.g. Wu et al., 1999; Baud et al., 1999).

We have reviewed water-weakening effect on sandstone. However, the theoretical model may also be generalized to fluids other than water. Further systematic studies in the laboratory will elucidate additional aspects of the environmental effects of fluid on mechanical compaction. It should also be noted that "chemical" compaction is also important, and other articles in this issue will address this topic. In reservoir and tectonic settings, deformation and fluid transport are usually coupled. A full analysis of the coupled problem requires data on the evolution of permeability as a function of stress. Some systematic studies (e.g. Zhu and Wong, 1997a; Wong and Zhu, 1999) have been conducted on this question, but it is beyond the scope of the present paper to review this important topic.

\section{ACKNOWLEDGMENTS}

Christian David, Beatriz Menéndez, Veronika Vajdova, Xiang Yang $\mathrm{Wu}$, and Wenlu Zhu have contributed to the research reviewed here. We have also benefited from numerous discussions with Yves Bernabé, Maurice Boutéca, Joanne Fredrich, Yves Guéguen, Florian Lehner, Philip Meredith, and Peter Schutjens. This research was partially supported by the Office of Basic Energy Sciences, Department of Energy, under grant DEFG0294ER14455.

\section{REFERENCES}

Ashby, M.F., and Sammis, C.G. (1990) The Damage Mechanics of Brittle Solids in Compression. PAGEOPH, 133, 489-521.

Atkinson, B.K. and Meredith, P.G. (1987) Experimental Fracture Mechanics Data for Rocks and Minerals. In Fracture Mechanics of Rock, Atkinson, B.K. (ed.), 477-525, Academic Press, London.

Baud, P., Zhu, W. and Wong, T.F. (1999) Failure Mode and Weakening Effect of Water on Sandstone. J. Geophys. Res., submitted.

Bernabé, Y. and Brace, W.F. (1990) Deformation and Fracture of Berea Sandstone. In The Heard Volume, 91-101, Am. Geophys. Union Geophysical Monograph.

Chen, W.F. (1984) Soil Mechanics, Plasticity and Landslides. In Mechanics of Inelastic Materials, Dvorak, G.J. and Shield, R.T. (eds.), 31-58, Elsevier, Amsterdam.

Curran, J.H. and Carroll, M.M. (1979) Shear Stress Enhancement of Void Compaction, J. Geophys. Res., 84, 1105-1112.

David, C., Wong, T.F., Zhu, W. and Zhang, J. (1994) Laboratory Measurement of Compaction-Induced Permeability Change in Porous Rock: Implications for the Generation and Maintenance of Pore Pressure Excess in the Crust. Pure Appl. Geophys., 143, 425-456.

Davis, P.B. (1991) Evaluation of the Role of Threshold Pressure in Controlling Flow of Waste-Generated Gas into Bedded Salt at the Waste Isolation Pilot Plant, Sandia National Laboratories.

Desai, C.S., and Siriwardane, H.J. (1984) Constitutive Laws for Engineering Materials, Prentice-Hall, Englewood Cliffs, NJ.

DiMaggio, F.L. and Sandler, I.S. (1971) Material Model for Granular Soils. J. Eng. Mech. Div., ASCE, 97, 935-950.

Drucker, D.C. (1951) A More Fundamental Approach to Plastic Stress Strain Relations. In Proc. First US National Congress Appl. Mechanics, 487-491.

Edmond, J.M., and Paterson, M.S. (1972) Volume Change During the Deformation of Rocks at High Pressure. Int. J. Rock Mech. Min. Sci., 9, 161-182.

Elliott, G.M., and Brown, E.T. (1985) Yield of a Soft, High Porosity Rock. Geotechnique, 35, 413-423.

Fredrich, J.T., Deitrick, G.L., Arguello, J.G., and de Rouffignac, E.P. (1998) Reservoir Compaction, Surface Subsidence, and Casing Damage: A Geomechanics Approach to Mitigation and Reservoir Management. In Eurock- Rock Mechanics in Petroleum Engineering, 403-412, SPE/ISRM 47284.

Goldsmith, A.S. (1989) Permeability Decline and Compressibility in Sandstone Reservoir Rocks, in Rock at Great Depth, 
Maury, V. and Fourmaintraux, D. (eds.), 923-928, A.A. Balkema, Rotterdam, The Netherlands.

Griffith, A.A. (1920) The Phenomena of Rupture and Flow in Solids. Phil. Trans. Roy. Soc., A221, 163-198.

Handin, J., Hager, R.V., Friedman, M. and Feather, J.N. (1963) Experimental Deformation of Sedimentany Rock under Confining Pressure: Pore Pressure Effects. Bull. Am. Asso. Petrol. Geol., 47, 717-755.

Horii, H. and Nemat-Nasser, S. (1986) Brittle Failure in Compression: Splitting, Faulting and Brittle-Ductile Transition. Phil. Trans. Roy. Soc. London, 319, 337-374.

Irwin, G.R. (1958) Fracture. In Handbuck der Physik, edited by S. Flugge, Springer-Verlag, Berlin.

Jamison, W.R. and Stearns, D.W. (1982) Tectonic Deformation of Wingate Sandstone, Colorado National Monument. Am. Asso. Pet. Geol. Bull., 66, 2584-2608.

Jamison, W.R. and Teufel, L.W. (1979) Pore Volume Changes Associated with Failure and Frictional Sliding of a Porous Sandstone, Proc. US Rock Mech. Symp., 20, 163-170.

Johnson, K.L. (1985) Contact Mechanics, Cambridge University Press, Cambridge.

Jones, M.E., and Leddra, M.J. (1989) Compaction and Flow of Porous Rocks at Depth. In Rock at Great Depth, Maury, V. and Fourmaintraux, D. (eds.), 891-898, A.A. Balkema, Rotterdam, The Netherlands.

Kemeny, J.M., and Cook, N.G.W. (1991) Micromechanics of Deformation in Rocks. In Toughening Mechanisms in QuasiBrittle Materials, Shah, S.P. (ed.), 155-188, Klewer Academic.

Lajtai, E.Z., Schmidtke, R.H. and Bielus, L.P. (1987) The Effect of Water on the Time-Dependent Deformation and Fracture of Granite. Int. J. Rock Mech. Min. Sci., 24, 247-255.

Menéndez, B., Zhu, W. and Wong, T.F. (1996) Micromechanics of Brittle Faulting and Cataclastic Flow in Berea Sandstone. J. Struct. Geol., 18, 1-16.

Orowan, E. (1944) The Fatigue of Glass under Stress. Nature, 154, 341-343.

Paterson, M.S. (1978) Experimental Rock Deformation. The Brittle Field, Springer-Verlag, New York.

Read, M.D., Ayling, M.R., Meredith, P.G. and Murrell, S.A.F. (1995) Microcracking During Triaxial Deformation of Porous Rocks Monitored by Changes in Rock Physical Properties. II. Pore Volumometry and Acoustic Emission Measurements on Water-Saturated Rocks. Tectonophysics, 245, 223-236.

Rehbinder, P.A., Schreiner, L.A. and Zhigach, K.F. (1948) Hardness Reducers in Drilling, Translation of 1944 Russian Book. Melbourne: Council for Scientific and Ind. Res., 78.

Schofield, A.N. and Wroth, C.P. (1968) Critical State Soil Mechanics, McGraw Hill, New York.

Schulson, E.M. and Nickolayev, O.Y. (1995) Failure of Columnar Saline Ice under Biaxial Compression: Failure Envelopes and the Brittle-Ductile Transition. J. Geophys. Res., 100, 22383-22400.
Senseny, P.E., Fossum, A.F. and Pfeifle, T.W. (1983) NonAssociative Constitutive Laws for Low-Porosity Rocks. Int. J. Num. Anal. Meth. Geomech., 7, 101-115.

Smits, R.M.M., de Waal, J.A. and Van Kooten, J.F.C. (1988) Prediction of Abrupt Reservoir Compation and Surface Subsidence Caused by Pore Collapse in Carbonates. SPE Form. Eval., 340-346.

Suarez-Rivera, F.R., Cook, N.G.W., Cooper, G.A. and Zheng, Z. (1990) Indentation by Pore Collapse in Porous Rocks. In Rock Mechanics Contributions and Challenges, Proceedings of the 31st U.S. Symposium on Rock Mechanics, Hustrulid, W.A. and Johnson, G.A. (eds.), 653-660, Balkema, Rotterdam, Netherlands.

Teufel, L.W., Rhett, D.W. and Farrell, H.E. (1991) Effect of Reservoir Depletion and Pore Pressure Drawdown on In Situ Stress and Deformation in the Ekofisk Field, North Sea. Proc. US Rock Mech. Symp., 32, 63-72.

Thiercelin, M. (1989) Parameters Controlling Rock Indentation. In Rock at Great Depth, Maury, V. and Fourmaintraux, D. (eds.), 85-92, A.A. Balkema, Rotterdam, The Netherlands.

Wilshaw, T.R. (1971) The Hertzian Fracture Test. J. Phys., D4, 1567-1581.

Wong, T.F., David, C. and Zhu, W. (1997) The Transition from Brittle Faulting to Cataclastic Flow in Porous Sandstones: Mechanical Deformation. J. Geophys. Res., 102, 3009-3025.

Wong, T.F., Szeto, H. and Zhang, J. (1992) Effect of Loading Path and Porosity on the Failure Mode of Porous Rocks. Appl. Mech. Rev., 45, 281-293.

Wong, T.F. and Zhu, W. (1999) Brittle Faulting and Permeability Evolution: Hydromechanical Measurement, Microstructural Observation, and Network Modeling. American Geophysical Union Monograph, 113, 83-99.

Wood, D.M. (1990) Soil Behaviour and Critical State Soil Mechanics, Cambridge University Press, Cambridge.

Wu, X.Y., Baud, P. and Wong, T.F. (1999) Micromechanics of Compressive Failure and Spatial Evolution of Anisotropic Damage in Darley Dale Sandstone. Int. J. Rock Mech. Min. Sci., in press.

Zhang, J., Wong, T.F. and Davis, D.M. (1990a) Micromechanics of Pressure-Induced Grain Crushing in Porous Rocks. $J$. Geophys. Res., 95, 341-352.

Zhang, J., Wong, T.F., Yanagidani, T. and Davis, D.M. (1990b) Pressure-Induced Microcracking and Grain Crushing in Berea and Boise Sandstones: Acoustic Emission and Quantitative Microscopy Measurements. Mech. Mater., 9, 1-15.

Zhu, W. and Wong, T.F. (1997a) Shear-Enhanced Compaction in Sandstone under Nominally Dry and Water-Saturated Conditions. Int. J. Rock Mech. Min. Sci., 34, 3/4, 364.

Zhu, W. and Wong, T.F. (1997b) The Transition from Brittle Faulting to Cataclastic Flow: Permeability Evolution. J. Geophys. Res., 102, 3027-3041. 